Research Article

\title{
Effect of Surface Shape and Content of Steel Fiber on Mechanical Properties of Concrete
}

\author{
Lijuan Zhang $\mathbb{D}^{1}{ }^{1}$ Jun Zhao, ${ }^{1}$ Cunyuan Fan, ${ }^{2}$ and Zhi Wang ${ }^{1}$ \\ ${ }^{1}$ School of Mechanics and Safety Engineering, Zhengzhou University, No. 100 Science Avenue, Zhengzhou 450001, Henan, China \\ ${ }^{2}$ School of Civil Engineering, Zhengzhou University, No. 100 Science Avenue, Zhengzhou 450001, Henan, China \\ Correspondence should be addressed to Lijuan Zhang; floycn526@163.com
}

Received 24 May 2020; Revised 22 June 2020; Accepted 27 June 2020; Published 21 July 2020

Academic Editor: Grzegorz Golewski

Copyright (C) 2020 Lijuan Zhang et al. This is an open access article distributed under the Creative Commons Attribution License, which permits unrestricted use, distribution, and reproduction in any medium, provided the original work is properly cited.

Steel fiber reinforced concrete (SFRC) has gained popularity in the last decades attributed to the improvement of brittleness and low tensile strength of concrete. This study investigates the effect of three shapes of steel fibers (straight, hooked end, and corrugated) with four contents $(0.5 \%, 1 \%, 1.5 \%$, and $2 \%)$ on the mechanical properties (compression, splitting tension, shear, and flexure) of concrete. Thirteen groups of concrete were prepared and investigated experimentally. Test results indicated that steel fiber had significant reinforcement on mechanical properties of concrete. When the steel fiber content increases from $0.5 \%$ to $2.0 \%$, the compressive strengths increase about $4-24 \%$, splitting tensile strengths increase about $33-122 \%$, shear strengths increase about $31-79 \%$, and flexural strengths increase about $25-111 \%$. Corrugated steel fiber has the best reinforced effect on strength of SFRC, hooked end steel fiber takes the second place, and straight steel fiber is the least. Calculated formulas of compressive, splitting tensile, shear, and flexural strengths were established with consideration of the bonding properties between concrete and steel fiber. Influence factors of steel fiber $\left(\alpha_{\mathrm{f}}\right)$ and concrete matrix strength $\left(\alpha_{\mathrm{c}}\right)$ were put forward and determined by regression analysis of experimental data. Calculated results agree well with the experimental results.

\section{Introduction}

Concrete is the largest amount and the most widely used material; its tensile strength is significantly lower than its compressive strength. Synthetic, glass, basalt, carbon, PVA, and steel fiber have been used in concrete to make up for the low tensile strength of concrete [1]. Fiber can notably enhance mechanical performance of concrete [2-4]. Compared with other fibers, steel fiber has many advantages, such as high stiffness and elasticity modulus and tensile strength. Steel fiber reinforced concrete (SFRC) has excellent tensile and flexural property $[5,6]$, which has been widely used as structural material. In order to improve the reinforced effect of steel fiber, the reinforced mechanism of steel fiber on concrete had been researched widely [7, 8]. Reinforced effect of steel fiber is mainly affected by fiber content, type, geometry, and strength of concrete matrix [9]. When the concrete matrix is fixed, the fiber content, type, and geometry are the main influence factors $[10,11]$.
It is generally acknowledged that the mechanical property of SFRC increases with the rising of steel fiber content. However, some studies suggest that steel fiber does not significantly affect the compressive strength [3]. The axial compressive strength almost keeps unchanged when the volume fraction of steel fiber is larger than $1.0 \%$ [12]. Other studies suggest that compressive strength increases by $25 \%$ with the volume fraction of steel fiber increasing from $0.5 \%$ to $1.5 \%$ for the moderately high strength concrete [13]. Some literatures have proved that steel fiber added in concrete increases the compressive strength of concrete by about $4-19 \%[14,15]$. Steel fiber in concrete significantly increases the split tensile and flexural strength of concrete [12]. Split tensile strength of SFRC is higher about $11-54 \%$ than the reference mixture. Besides, flexural strengths of SFRC are higher by $3-81 \%$ than reference mixture. In addition, the increase ratio of flexural strength is higher than that of the split tensile and compressive strength [16]. Shear strength increases by $44 \%$ for the steel fiber volume fraction 
of $0.5 \%$ and $65 \%$ for the volume ratio of $1 \%$ [17]. The shear strength of SFRC exhibits a linear increase with the amount of steel fiber crossing the shear crack interface [18]. It can be seen that even if the content of steel fiber is the same, steel fiber still has different reinforced effect on different mechanical property. In a word, the reinforced effect of steel fiber on concrete strength still has not uniform answer.

According to manufacturing form, steel fiber is usually classified into three main shapes (straight form, hooked ends form, and corrugated form) [11, 19]. Different steel fiber shapes have different effect on the mechanical performance of concrete due to the different bond property. However, some researchers suggest that steel fiber shape almost has no influence on compressive strength [12] or the compressive performance is insignificantly affected by the length and type of fiber [20]. The compressive strength and the elastic modulus of SFRC were developed with hooked end steel fiber [21]. The compressive strength is improved by twisted steel fiber compared to short straight steel fiber, but the improvement is relatively insignificant compared to what is observed for the tensile and flexural performance [22]. The tensile strength is improved by using the deformed steel fiber, as compared to that with the short straight steel fiber [23]. The specimens with $2 \%$ of twisted steel fiber exhibit a tensile strength which is approximately 32\% higher than those with $2 \%$ of short straight steel fiber. Previous research has showed that corrugated and hooked fiber significantly improved the bond properties by three to seven times when compared to those with straight fiber $[24,25]$. It can be concluded that even if the content of steel fiber is the same, the different shape steel fiber has different effect on concrete mechanical property.

Although much work has been done about SFRC, there still exists unsolved problem:

(i) Although the reinforced effect of steel fiber on compressive strength is much less than that on tensile strength, shear strength, and flexural strength, the increase ratio of compressive strength still can reach $25 \%$ for low or moderately high strength $(\leq 60 \mathrm{MPa})$ concrete. Some literature studies suggest that steel fiber shape almost has no influence on compressive strength; others indicate that compressive strength can be improved by steel fiber no matter what type steel fiber is. There are still many different conclusions about the reinforced effect of steel fiber on compressive strength, so the reinforced effect of steel fiber with different content and type on compressive strength should be studied further.

(ii) Splitting tensile, flexure, and shear strength of SFRC increase with the rising of steel fiber content; some researchers suggest that concrete strength will no longer increase when steel fiber content exceeds a certain value, which means that there exists the most economical steel fiber content for certain strength. But there is no final word on the most economical content of steel fiber. (iii) The shape of steel fiber has significantly influence on the enhancement effect of splitting tensile, flexure, and shear strength of SFRC. At the same time, the reinforced effect of different shapes on various mechanical properties of concrete is also different. So, there is the best shape of steel fiber which can achieve the best enhancement effect on one kind of mechanical property of content.

How to determine the optimal content and shape of steel fiber is an important problem. This would help improve the utilization rate of steel fiber and reduce the cost of SFRC.

In this research, the impact of steel fiber shape and content on the reinforced effect of concrete will be monitored and analyzed through the compressive, splitting tensile, shear, and flexural experiments. Three shapes (straight, hooked end, and corrugated) of steel fiber were used to research the influence on the mechanical performance of concrete with different volume fractions $(0,0.5 \%$, $1 \%, 1.5 \%$, and $2 \%)$. Based on the test result, calculation model of compressive, splitting tensile, shear, and flexural strength of SFRC were put forward.

\section{Experiment Investigation}

2.1. Materials. Portland cement (P. O. 42.5) conforming to GB 175 [26] was used in all mixes; properties of the cement are shown in Table 1. The coarse aggregate was crushed limestone with continuous grading of particle sizes from $4.75 \mathrm{~mm}$ to $20 \mathrm{~mm}$. Fine aggregate was river sand with a fineness modulus of 2.7. Properties of all aggregates used in the test are shown in Table 2 according to the Chinese Standard GB/T 14685 [27]. Three shapes of steel fiber, namely, straight (ST-F), hooked end (HE-F), and corrugated (CO-F) were used in tests. Geometry and mechanical characteristics of steel fiber are listed in Table 3. Four different volume fractions of steel fiber were developed to cover the majority of practically used fractions range: $0.5 \%, 1.0 \%$, $1.5 \%$, and $2 \%$.

2.2. Mix Proportion. Three shapes of steel fiber and four steel fiber volume fractions $\left(V_{\mathrm{f}}=0.5 \%, 1.0 \%, 1.5 \%\right.$, and $\left.2 \%\right)$ were chosen as test parameters. Steel fiber volume fraction $\left(V_{\mathrm{f}}\right)$ was defined as the absolute volume of steel fiber in $1 \mathrm{~m}^{3}$ concrete. Water-cement ratio was taken as 0.55 . The mixture proportion design method conformed to the Chinese Standards JGJ 55-2011 [28] and JG/T 472-2015 [29]. The target slump was taken as $180 \mathrm{~mm}$. The sand ratio of plain concrete was taken as $42 \%$. In order to ensure the working performance of concrete, the sand rate increases by $1 \%$ when the steel fiber volume fraction increases by $1 \%$. Details of mixture proportion designs are listed in Table 4. PC represents plain concrete for comparison; letters represent the type of steel fiber; numbers represent the steel fiber volume fraction (\%), such as ST-F0.5; it means that straight steel fiber and steel fiber volume fraction is $0.5 \%$. 
TABle 1: Physical and mechanical properties of cement.

\begin{tabular}{|c|c|c|c|c|c|c|c|c|c|c|}
\hline \multirow[t]{2}{*}{ Type } & \multirow[t]{2}{*}{$\begin{array}{c}\text { Specific } \\
\text { gravity }\left(\mathrm{kg} / \mathrm{m}^{3}\right)\end{array}$} & \multirow[t]{2}{*}{$\begin{array}{c}\text { Surface } \\
\text { area }\left(\mathrm{m}^{2} / \mathrm{kg}\right) \%\end{array}$} & \multirow[t]{2}{*}{$\begin{array}{c}\text { Standard } \\
\text { consistency }\end{array}$} & \multirow[t]{2}{*}{ Stability } & \multicolumn{2}{|c|}{$\begin{array}{l}\text { Setting time } \\
\quad(\min )\end{array}$} & \multicolumn{2}{|c|}{$\begin{array}{l}\text { Compressive } \\
\text { strength } \\
(\mathrm{MPa})\end{array}$} & \multicolumn{2}{|c|}{$\begin{array}{c}\text { Flexural } \\
\text { strength } \\
(\mathrm{MPa})\end{array}$} \\
\hline & & & & & Initial & Final & $3 \mathrm{~d}$ & $28 \mathrm{~d}$ & $3 \mathrm{~d}$ & $28 \mathrm{~d}$ \\
\hline P. O. 42.5 & 3100 & 352 & 24.7 & Eligibility & 175 & 220 & 23.5 & 45 & 5.6 & 8.5 \\
\hline
\end{tabular}

TABLe 2: Physical properties of the coarse and fine aggregate.

\begin{tabular}{|c|c|c|c|c|c|c|}
\hline Aggregate type & $\begin{array}{c}\text { Apparent density } \\
\left(\mathrm{kg} / \mathrm{m}^{3}\right)\end{array}$ & $\begin{array}{l}\text { Loose packing density } \\
\left(\mathrm{kg} / \mathrm{m}^{3}\right)\end{array}$ & $\begin{array}{l}\text { Dry-rodded density } \\
\left(\mathrm{kg} / \mathrm{m}^{3}\right)\end{array}$ & $\begin{array}{l}\text { Water absorption } \\
(\text { wt \%) }\end{array}$ & $\begin{array}{c}\text { Crush index } \\
(\%)\end{array}$ & $\begin{array}{c}\text { Void ratio } \\
(\%)\end{array}$ \\
\hline $\begin{array}{l}\text { Coarse } \\
\text { aggregate }\end{array}$ & 2814 & 1568 & 1630 & 1.40 & 8.8 & 44.3 \\
\hline Fine aggregate & 2556 & 1611 & 1486 & 0.56 & - & - \\
\hline
\end{tabular}

TABLE 3: Geometry and mechanical characteristics of steel fibers.

\begin{tabular}{lccc}
\hline & ST-F & HE-F & CO-F \\
\hline Fiber shape & Straight & Hooked end & Corrugated \\
Mean length $\left(l_{\mathrm{f}}\right), \mathrm{mm}$ & 32.34 & 32.19 & 32.27 \\
Mean diameter $\left(\mathrm{d}_{\mathrm{f}}\right), \mathrm{mm}$ & 1.036 & 0.993 & 1.215 \\
Aspect ratio $\left(l_{\mathrm{f}} / \mathrm{d}_{\mathrm{f}}\right)$ & 31.21 & 32.41 & 26.56 \\
Density $\left(\mathrm{g} / \mathrm{cm}^{3}\right)$ & 7.9 & 7.9 & 7.9 \\
Elastic modulus $(\mathrm{GPa})$ & 200 & 200 & 200 \\
Tensile strength $(\mathrm{MPa})$ & 500 & 380 & 500 \\
\hline
\end{tabular}

TABle 4: Mixture proportions $\left(\mathrm{kg} / \mathrm{m}^{3}\right)$.

\begin{tabular}{lccccc}
\hline Mixture number & Water & Cement & Sand & Stone & Steel fiber \\
\hline PC & 264 & 480 & 716.5 & 989.5 & 0 \\
ST-F0.5 & 264 & 480 & 727.8 & 965.8 & 39 \\
ST-F1 & 264 & 480 & 739.2 & 942.3 & 78 \\
ST-F1.5 & 264 & 480 & 750.5 & 917.3 & 117 \\
ST-F2 & 264 & 480 & 761.9 & 895.1 & 156 \\
HE-F0.5 & 264 & 480 & 727.8 & 965.8 & 39 \\
HE-F1 & 264 & 480 & 739.2 & 942.3 & 78 \\
HE-F1.5 & 264 & 480 & 750.5 & 917.3 & 117 \\
HE-F2 & 264 & 480 & 761.9 & 895.1 & 156 \\
CO-F0.5 & 264 & 480 & 727.8 & 965.8 & 39 \\
CO-F1 & 264 & 480 & 739.2 & 942.3 & 78 \\
CO-F1.5 & 264 & 480 & 750.5 & 917.3 & 117 \\
CO-F2 & 264 & 480 & 761.9 & 895.1 & 156 \\
\hline
\end{tabular}

2.3. Test Specimen. The cubic specimens with side length of $150 \mathrm{~mm}$ were cast for the compressive strength $\left(f_{\mathrm{cu}}, f_{\mathrm{fcu}}\right)$ and splitting tensile strength $\left(f_{\mathrm{ts}}, f_{\mathrm{fts}}\right)$ test, the prism specimens of $100 \mathrm{~mm} \times 100 \mathrm{~mm} \times 300 \mathrm{~mm}$ were cast for shear strength $\left(f_{\mathrm{v}}\right.$, $f_{\mathrm{fv}}$ ) test, the prism specimens of $100 \mathrm{~mm} \times 100 \mathrm{~mm} \times 400 \mathrm{~mm}$ were cast for flexural strength $\left(f_{\mathrm{tm}}, f_{\mathrm{ftm}}\right)$ test, and three specimens were prepared for each group. To distinguish the concrete with and without steel fiber, $f_{\mathrm{cu}}, f_{\mathrm{ts}}, f_{\mathrm{v}}$, and $f_{\mathrm{tm}}$ are used to represent the mechanical performance indexes of the plain concrete; $f_{\mathrm{fcu}}, f_{\mathrm{fts}}, f_{\mathrm{fv}}$, and $f_{\mathrm{ftm}}$ are used to represent the mechanical performance indexes of SFRC.
A multifunction mixer was used to prepare the concrete. Mixing process of concrete included three steps: firstly, all aggregate and cement were put into a forced concrete mixer to mix for about 2 minutes; secondly, the water was added and mixed continuously for 2 minutes; finally, steel fiber was sprinkled evenly and then mixed for another 3 minutes. Fresh concrete was put rapidly into the moulds which were brushed oil in advance. Specimens were vibrated for 20 seconds. After 24 hours of curing in air, specimens were carefully demoulded and placed in a curing room at approximately $95 \% \mathrm{RH}$ and $20^{\circ} \mathrm{C}$.

2.4. Test Method. All the tests were conducted at the age of 28 days. The compressive strength and splitting tensile strength test were performed according to GB/T50081 [30] and were carried on a servohydraulic closed-loop testing machine with capacity of $3000 \mathrm{kN}$ at the loading rate of $0.6 \mathrm{MPa} / \mathrm{s}$ and $0.06 \mathrm{MPa} / \mathrm{s}$, respectively. Test setup of splitting tensile test is shown in Figure 1.

One steel bearing plate and one plywood bearing strip were placed between specimen and the top and bottom pressure plate, respectively. The section of bearing plate is part of circle radius of $75 \mathrm{~mm}$; thickness is $20 \mathrm{~mm}$. The section of bearing strip is $20 \mathrm{~mm} \times 4 \mathrm{~mm}$. The bearing plate and bearing strip should align with the center line of the top and bottom surface of specimen. The splitting tensile strength of the specimen was calculated as follows:

$$
f_{f t s}=0.637 \frac{F}{A},
$$

where $f_{\text {fts }}$ is the splitting tensile strength, MPa; $F$ is the maximum applied load indicated by the testing machine, $\mathrm{N}$; $A$ is the area of splitting surface, $\mathrm{mm}^{2}$.

The shear test was also carried on a servohydraulic closed-loop testing machine with capacity of $3000 \mathrm{kN}$ at the loading rate of $0.06 \mathrm{MPa} / \mathrm{s}$; the test setup is shown in Figure 2.

The load was recorded with a load transducer. The ultimate shear strength was calculated as follows: 

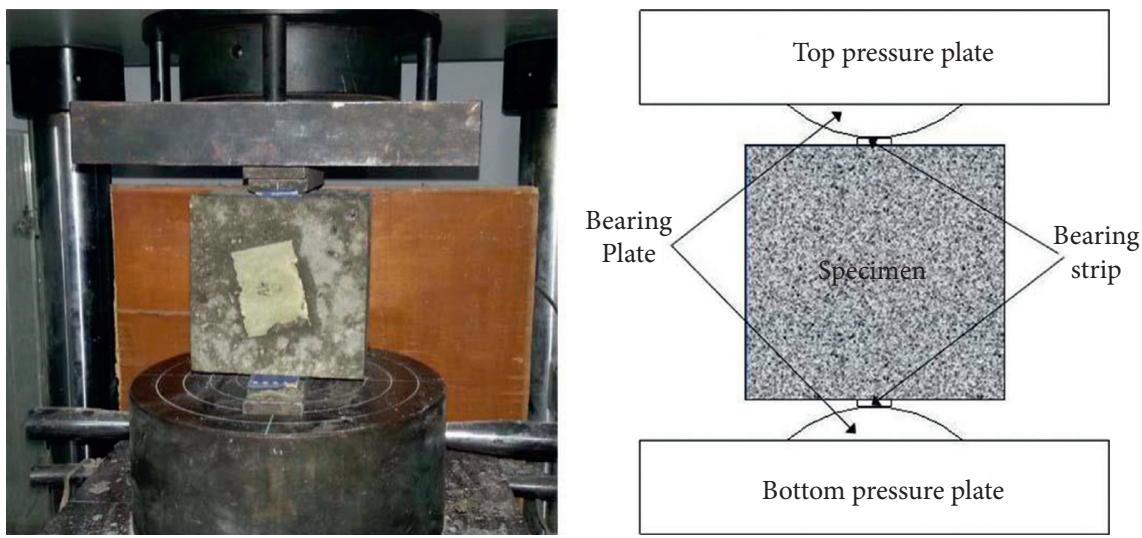

FIgURE 1: Test setup of splitting tensile strength.
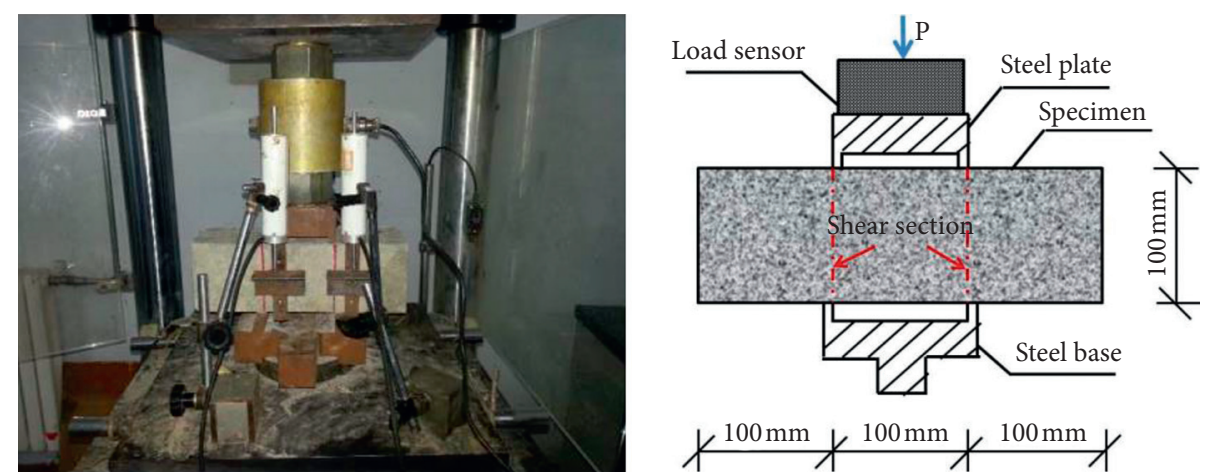

Figure 2: Test setup of shear strength.

$$
f_{\mathrm{fv}}=\frac{F}{2 b_{\mathrm{eff}} d_{\mathrm{eff}}},
$$

where $f_{\mathrm{fv}}$ is the ultimate shear strength; $\mathrm{F}$ is the maximum applied load indicated by the testing machine; $b_{\text {eff }}$ is the effective width of the specimen (the average value of the width of the two shear sections), and $d_{\text {eff }}$ is its effective depth (the average value of the depth of the two shear sections).

Flexural tests were carried on a MTS810 testing machine with capacity of $500 \mathrm{kN}$ with displacement control at a rate of $0.1 \mathrm{~mm} / \mathrm{min}$, according to ASTM C1609 (using beam with third-point loading) [31]. The test setup is shown in Figure 3.

The specimens were normally rotated an angle of $90^{\circ}$ from the casting position to eliminate the eccentricity effect from the roughness of the surface. Calculate the flexural strength of the specimen as follows:

$$
f_{\mathrm{ftm}}=\frac{F l}{b h^{2}}
$$

where $f_{\mathrm{ftm}}$ is flexural strength, $\mathrm{MPa} ; \mathrm{F}$ is the maximum applied load indicated by the testing machine, $\mathrm{N} ; b$ and $h$ are the average width and height of specimen, $\mathrm{mm} ; l$ is the span length of test specimen, $\mathrm{mm}$.

At least, three specimens in each group were tested and their mean values were taken as the test results. Test results of $f_{\mathrm{fcu}}, f_{\mathrm{fts}}, f_{\mathrm{fv}}$, and $f_{\mathrm{ftm}}$ are listed in Table 5 .

\section{Test Results and Discussion}

3.1. Compressive Strength. Relationship between compressive strength $\left(f_{\mathrm{fcu}}\right)$, compressive strength reinforced ratio $\left(f_{\mathrm{fcu}} / f_{\mathrm{cu}}\right)$, and steel fiber volume fraction $\left(V_{\mathrm{f}}\right)$ with the different steel fiber shape are shown in Figure 4.

In general, $f_{\text {fcu }}$ increased continuously as $V_{\mathrm{f}}$ increased from 0 to $2 \%$. However, the increasing trend has slight difference with the different steel fiber shape. When $V_{\mathrm{f}} \leq 1 \%$, the $f_{\mathrm{fcu}} / f_{\mathrm{cu}}$ of ST-F and HE-F was slightly bigger than that of CO-F. But, when $V_{\mathrm{f}}$ reached $2 \%, f_{\mathrm{fcu}} / f_{\mathrm{cu}}$ of CO-F reached its maximum value 1.24 , which was higher than $\mathrm{f}_{\mathrm{fcu}} / \mathrm{f}_{\mathrm{cu}}$ of ST-F and HE-F. It indicated that ST-F and HE-F had better strength reinforcement when $V_{\mathrm{f}}$ was below $1 \%$, while CO-F had better strength reinforcement when $V_{\mathrm{f}}$ was above $1 \%$. Although different steel fiber shape has reinforced effect on compressive strength of concrete, the increment is limited and the maximum value of $f_{\mathrm{fcu}} / f_{\mathrm{cu}}$ is 1.24 .

The steel fiber can limit the lateral expansion and restrain the crack propagation of concrete under compressive load, which can delay the damage of concrete and enhance the compressive performance. The reinforced effect is decided by the bonding performance between steel fiber and concrete. The bonding force is affected by the surface shape of steel fiber. So, the different surface shape has the different effect on the compressive strength of concrete. 

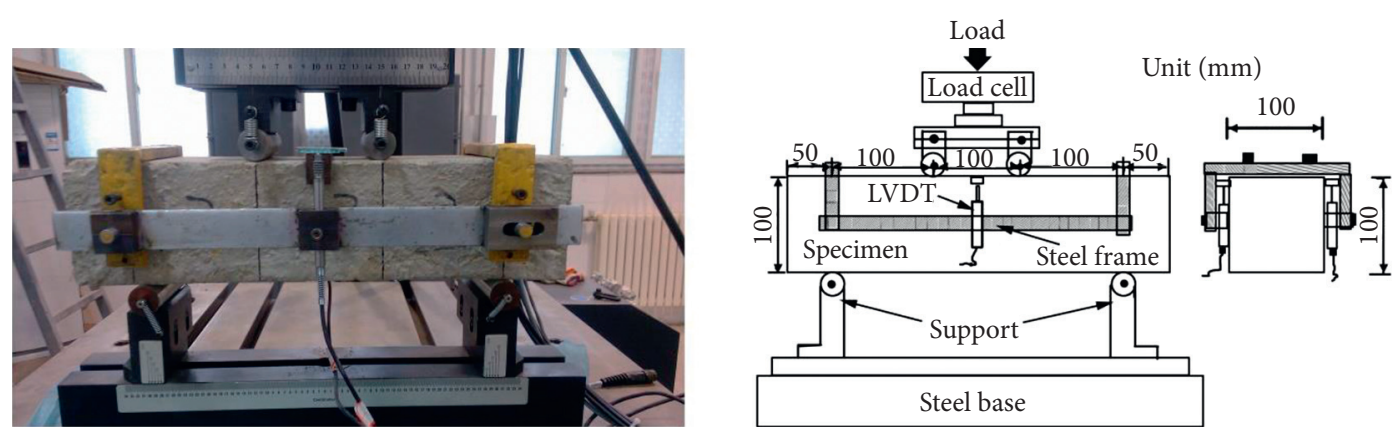

Figure 3: Test setup of flexural strength.

TABLE 5: Test results of mechanics strength (MPa).

\begin{tabular}{lcccr}
\hline Mixture number & $f_{\text {fcu }}$ & $f_{\text {fts }}$ & $f_{\text {fv }}$ & \\
\hline PC & 34.6 & 3.15 & 6.85 & \\
ST-F0.5 & 36 & 4.19 & 9.39 & 4.32 \\
ST-F1 & 38.8 & 4.45 & 10.20 & 11.06 \\
ST-F1.5 & 38.1 & 4.89 & 12.25 & 6.25 \\
ST-F2 & 40.8 & 5.34 & 10.01 & 7.39 \\
HE-F0.5 & 38.2 & 4.28 & 11.00 & 7.95 \\
HE-F1 & 38.1 & 5.20 & 12.21 & 6.09 \\
HE-F1.5 & 40.3 & 5.81 & 11.38 & 7.26 \\
HE-F2 & 41.6 & 6.41 & 9.80 & 7.55 \\
CO-F0.5 & 35 & 4.64 & 10.08 & 8.68 \\
CO-F1 & 37.7 & 5.30 & 12.01 & 6.58 \\
CO-F1.5 & 40.1 & 6.55 & 11.12 & 7.35 \\
CO-F2 & 42.9 & 7.00 & 8.51 \\
\hline
\end{tabular}
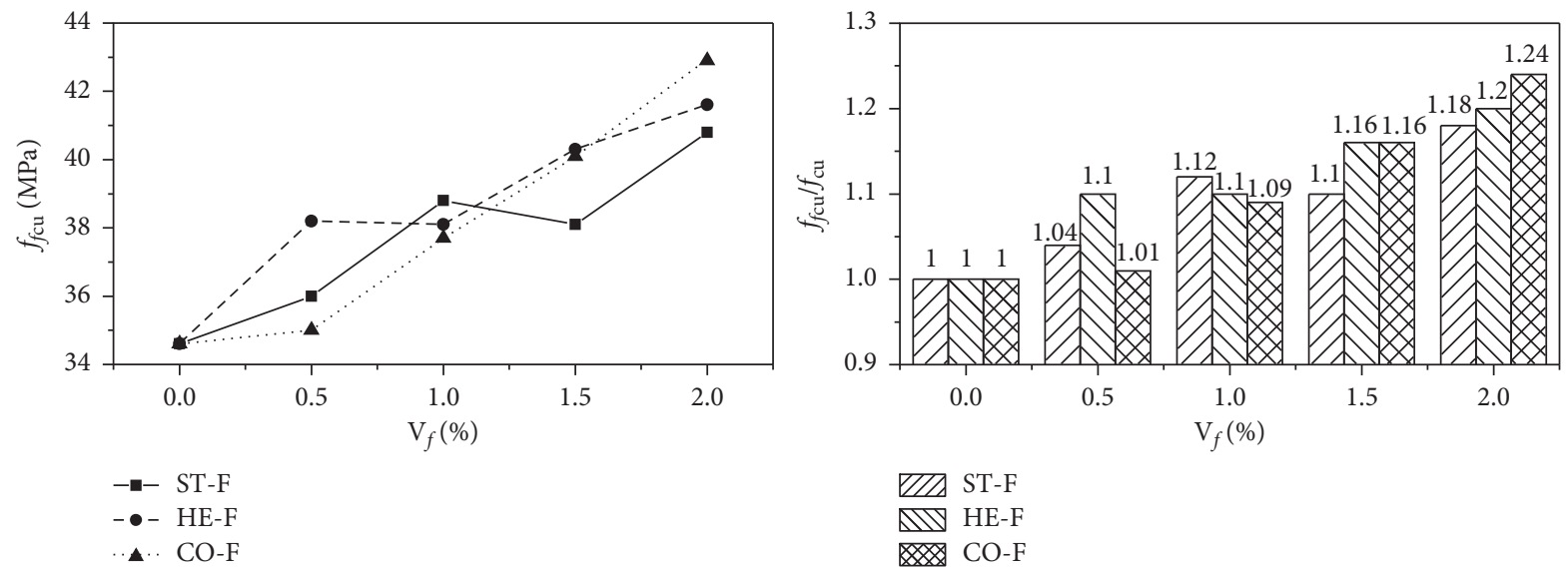

ZIA ST-F
HE-F
CO-F

Figure 4: Relationship between $f_{\text {fcu }}, f_{\text {fcu }} / f_{\text {cu }}$, and $V_{\mathrm{f}}$.

3.2. Tensile Strength. Relationship between splitting tensile strength $\left(f_{\mathrm{fts}}\right)$, splitting tensile strength reinforced ratio $\left(f_{\mathrm{fts}}\right)$ $f_{\mathrm{ts}}$ ), and steel fiber volume fraction $\left(V_{\mathrm{f}}\right)$ with the different steel fiber shape is shown in Figure 5. $f_{\mathrm{fts}}$ increased continuously as $V_{\mathrm{f}}$ increased from 0 to $2 \%$. When $V_{\mathrm{f}} \leq 0.5 \%$, ST$\mathrm{F}$ and HE-F have a similar reinforced effect on concrete; CO$\mathrm{F}$ has a slighter better reinforced effect than them. When $V_{\mathrm{f}} \geq 0.5 \%$, CO-F still has the best reinforced effect and HE-F takes the second place. When $V_{\mathrm{f}}=2 \%, f_{\mathrm{fts}} / f_{\mathrm{ts}}$ of CO-F is 2.22 , $f_{\mathrm{fts}} / f_{\mathrm{ts}}$ of HE-F is 2.03 , and $f_{\mathrm{fts}} / f_{\mathrm{ts}}$ of ST-F is only 1.7. As shown in 3 , these three types of steel fibers have similar length and diameter; the only difference is the surface shape. With the same steel fiber content, the reinforced effect can be improved dramatically by changing the surface shape of steel fiber.

Test results proved that $\mathrm{CO}-\mathrm{F}$ had the best reinforced effect on $f_{\mathrm{fts}}$. This is because the surface of CO-F is the shape of corrugate and it can provide higher interface bonding force than ST-F and HE-F. Similarly, HE-F with the hooked form at both ends can provide better interface bonding force than ST-F with straight surface. ST-F has the smallest reinforced effect on $f_{\mathrm{fts}}$ because its surface is smooth and can not provide the mechanical occlusive force. It can be seen that because the surface shape of steel fiber has important 

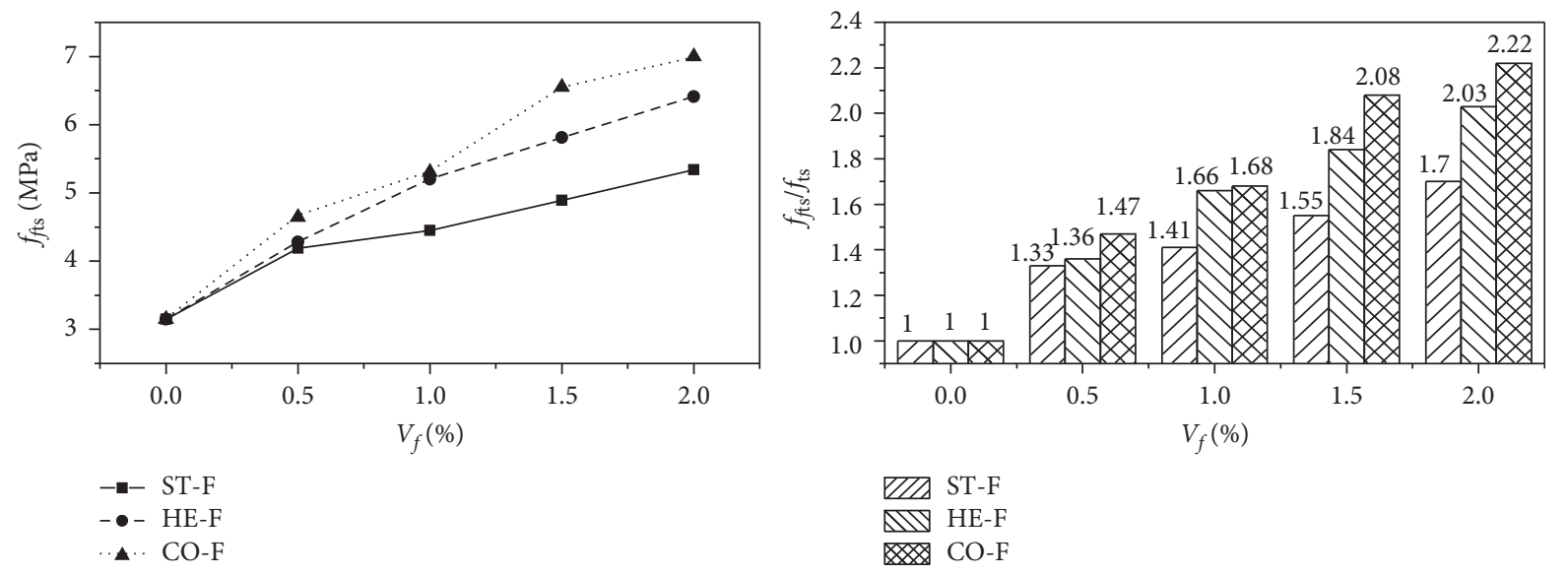

FIGURE 5: Relationship between $f_{\mathrm{fts}}, f_{\mathrm{fts}} / f_{\mathrm{ts}}$, and $V_{\mathrm{f}}$.

effect on the interface bonding force between concrete and steel fiber, the surface shape of steel fiber obviously affects the reinforced effect on the splitting tensile strength of concrete. In order to increase the reinforcement of steel fiber on concrete, the rough surface of steel fiber is the best choice.

3.3. Shear Strength. Relationship between shear strength $\left(f_{\mathrm{fv}}\right)$, shear strength reinforced ratio $\left(f_{\mathrm{fv}} / f_{\mathrm{v}}\right)$, and steel fiber volume fraction $\left(V_{\mathrm{f}}\right)$ with the different steel fiber shape is shown in Figure 6. When $V_{\mathrm{f}}$ increases from 0 to $0.5 \%, f_{\mathrm{fv}}$ increases rapidly. When $V_{\mathrm{f}}=0.5 \%, f_{\mathrm{fv}} / f_{\mathrm{v}}=1.37$ for ST-F, $f_{\mathrm{fv}} /$ $f_{\mathrm{v}}=1.46$ for HE-F, and $f_{\mathrm{fv}} / f_{\mathrm{v}}=1.43$ for CO-F. Whatever the steel fiber shape is, $f_{\mathrm{fv}}$ increases about $40 \%$ when $V_{\mathrm{f}}$ increases from 0 to $0.5 \%$. When $V_{\mathrm{f}}$ increases from 0.5 to $1.5 \%, f_{\mathrm{fv}}$ still increases with the increase of $V_{\mathrm{f}}$, but the growth ratio is slowing down. When $V_{\mathrm{f}}$ is more than $1.5 \%, \mathrm{f}_{\mathrm{fv}}$ of ST-F continuously increases while $f_{\text {fv }}$ decreases with the increase of $V_{\mathrm{f}}$ for HE-F and CO-F.

This result indicates that too much steel fiber can cause shear strength reduction. The reason lies in two aspects. One is that the compressive strength of concrete matrix is not high; it leads steel fiber which is pulled out from concrete matrix before concrete failure because of the low bond force between concrete and steel fiber. And steel fiber cannot give full play when the steel fiber volume fraction is big. Some literature gave a similar result: to improve the shear strength, the first way consists in the increase of the compressive strength of the concrete; the second way is obtained with the addition of fiber [14]. The other reason is that higher $V_{\mathrm{f}}$ may more easily cause the uneven distribution of steel fiber; the uneven distribution of steel fiber leads to the lower bonding force between some steel fiber and concrete and also produces some weakened region. An optimum steel fiber content exists for a given concrete, beyond which the reinforcing effect of steel fiber on the shear strength becomes weakened with increase of steel fiber content. This result is slightly different to many previous literatures which proved that direct shear capacity of SFRC is clearly related to the amount of fiber [15].
3.4. Flexural Strength. Relationship between flexural strength $\left(f_{\mathrm{ftm}}\right)$, flexural strength reinforced ratio $\left(f_{\mathrm{ftm}} / f_{\mathrm{tm}}\right)$, and steel fiber volume fraction $\left(V_{\mathrm{f}}\right)$ with the different steel fiber shape is shown in Figure $7 . f_{\mathrm{ftm}}$ increased continuously as $V_{\mathrm{f}}$ increased from 0 to $2 \%$. Whatever the shapes of steel fiber are, the three trend lines are nearly straight upward; this indicates that $f_{\mathrm{ftm}}$ is all nearly a linear function of $V_{\mathrm{f}}$. However, the slopes of three lines are different, the slope of $\mathrm{CO}-\mathrm{F}$ is the biggest, and the slope of ST-F is the least. This means that when $V_{\mathrm{f}}$ is fixed, the enhancement effect is different with the different shape of steel fiber. CO-F is the best and HE-F takes the second place. It can be attributed to the bond strength of the matrix and steel fiber. The deformed shape provides better bond property than the straight fiber.

When $V_{\mathrm{f}}$ reaches its maximum value $2 \%, f_{\mathrm{ftm}} / f_{\mathrm{tm}}$ of CO-F is 2.11 and $f_{\mathrm{ftm}} / f_{\mathrm{tm}}$ of HE-F is 2.01 ; this means that $f_{\mathrm{ftm}}$ of concrete in corrugated and hooked steel fiber doubles the value of plain concrete. $f_{\mathrm{ftm}} / f_{\mathrm{tm}}$ of ST-F is the least, which is 1.84. This proved that steel fiber has excellent enhancement effect on flexural strength. Previous research suggested that the limited volume fraction of HE-F is $1.5 \%$ for the economical and efficient use of steel fiber on flexural performance [11]. However, test results of this paper indicated that flexural strength still increased with $V_{\mathrm{f}}$, even if $V_{\mathrm{f}} \geq 1.5 \%$. This may be because the concrete matrix strength in this test is only about $40 \mathrm{MPa}$. The flexural failure is attributable mostly to pull-out rather than rupture of the steel fiber. The flexural strength of the SFRC increased with the increase of fiber content, which is closely related to the number of steel fibers that provide a bridging action. Then, steel fiber of deformed shape can play more important role than that with straight shape.

\section{Strength Calculation Model}

The above result analysis proved that steel fiber can improve $f_{\mathrm{fcu}}, f_{\mathrm{fts}}, f_{\mathrm{fv}}$, and $f_{\mathrm{ftm}}$ of concrete obviously with the increasing of $V_{\mathrm{f}}$. When $V_{\mathrm{f}}$ is fixed, the reinforcement ratio mainly is influenced by the interface bonding force between concrete and steel fiber. The interface bonding force mainly consists of three parts: chemical cementation force, frictional 

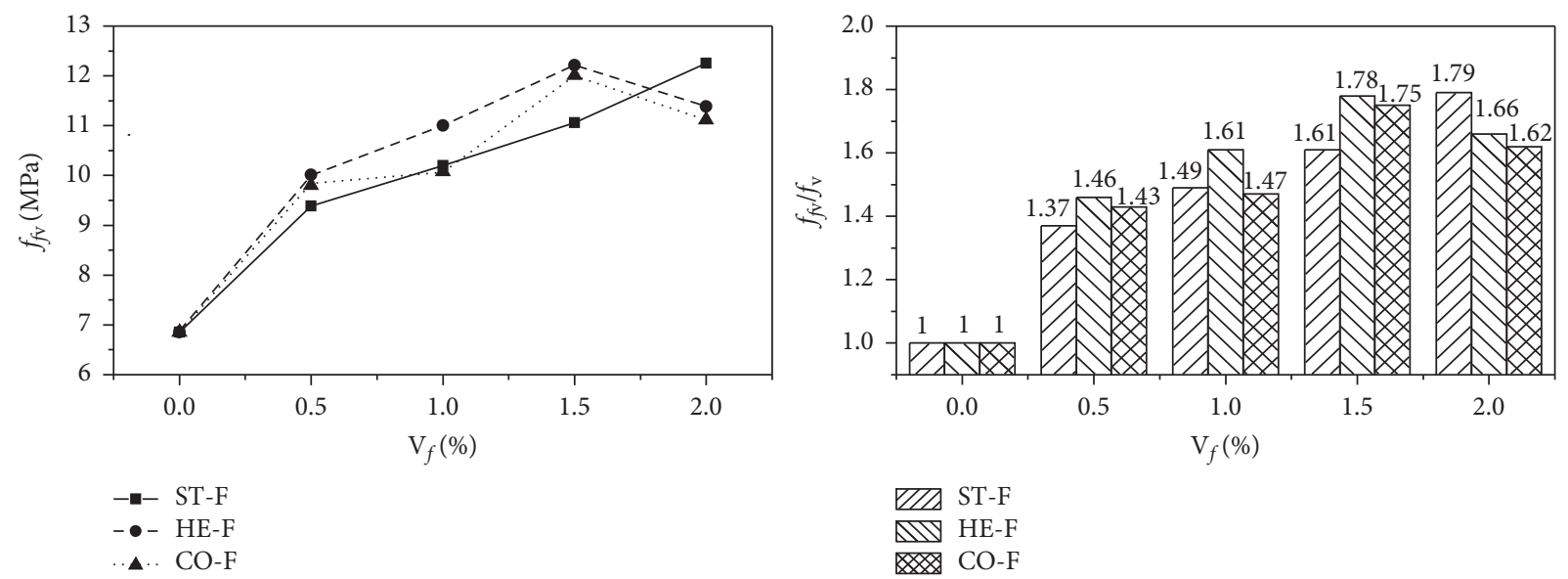

FIgURE 6: Relationship between $f_{\mathrm{fv}}, \mathrm{f}_{\mathrm{fv}} / f_{\mathrm{v}}$, and $V_{\mathrm{f}}$.
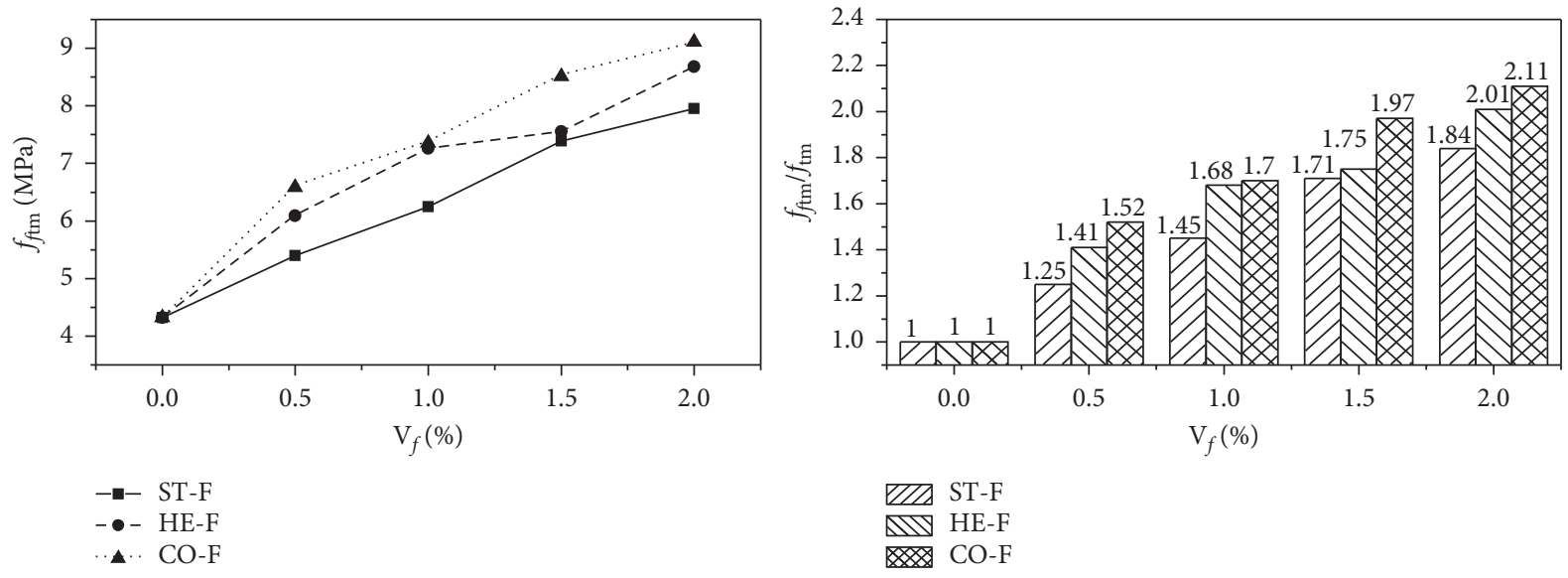

FIGURE 7: Relationship between $f_{\mathrm{ftm}}, f_{\mathrm{ftm}} / f_{\mathrm{tm}}$, and $V_{\mathrm{f}}$.

resistance, and mechanical interaction force. Chemical cementation force is mainly influenced by the strength of concrete matrix $\left(f_{\mathrm{cu}}\right)$. Frictional resistance is mainly affected by surface area and roughness. Mechanical occlusal force is mainly affected by the surface dents of steel fiber. Thus, the important enhancement factors of ffcu, $f_{f t s}, f_{f v}$, and $f_{f t m}$ are concrete matrices $\left(\mathrm{f}_{\mathrm{cu}}\right)$, aspect ratio $\left(\mathrm{l}_{\mathrm{f}} / \mathrm{d}_{\mathrm{f}}\right)$, content $\left(\mathrm{V}_{\mathrm{f}}\right)$, and shape and surface dents of steel fiber.

4.1. Effect of Steel Fiber. Based on the above analysis, reinforcement ratio of $f_{\mathrm{fcu}}$ is influenced by content, aspect ratio, and shape of steel fiber; it can be expressed as follows:

$$
\frac{f_{\text {fcu }}}{f_{\text {cu }}}=1+\alpha_{\mathrm{f}} \lambda_{\mathrm{f}},
$$

where $f_{\text {fcu }}$ is the compressive strength of SFRC; $f_{\text {cu }}$ is the compressive strength of plain concrete; $\alpha_{\mathrm{f}}$ is the influence coefficient of steel fiber shape, which is related to the geometric and surface shape of steel fiber; $\lambda_{\mathrm{f}}$ is the characteristic coefficient of steel fiber, $\lambda_{\mathrm{f}}=V_{\mathrm{f}} l_{\mathrm{f}} / d_{\mathrm{f}}$. $\alpha_{\mathrm{f}}$ of these three shapes steel fiber can be obtained through the regression analysis of experiment data in this paper and relative research literature $[13,16,32-35]$ based on (4). The relationship between $f_{\text {fcu }} / f_{\text {cu }}$ and $\lambda_{\mathrm{f}}$ is shown in Figure 8 .

As shown in Figure 8, although the length and aspect ratio of steel fiber from different literature are different, the reinforcement ratio of $f_{\text {fcu }}$ had a linear relationship with $\lambda_{\mathrm{f}}$ when the surface shape of steel fiber is the same. Value of $\alpha_{\mathrm{f}}$ can be obtained through regression analysis: $\alpha_{\mathrm{f}}=0.21$ for STF; $\alpha_{\mathrm{f}}=0.27$ for HE-F; $\alpha_{\mathrm{f}}=0.4$ for CO-F. $\alpha_{\mathrm{f}}$ of CO-F is the biggest; this is because corrugated surface not only can increase the surface roughness, but also can provide mechanical interaction force. $\alpha_{\mathrm{f}}$ of HE-F is in the second place; hooks at the end of steel fiber can increase part of the frictional resistance. Adding surface roughness or uneven of steel fiber can improve its enhancement effect obviously under the condition of keeping content of steel fiber.

4.2. Effect of Concrete Matrix. Concrete matrix also plays an important role in bonding strength, so it significantly affects 


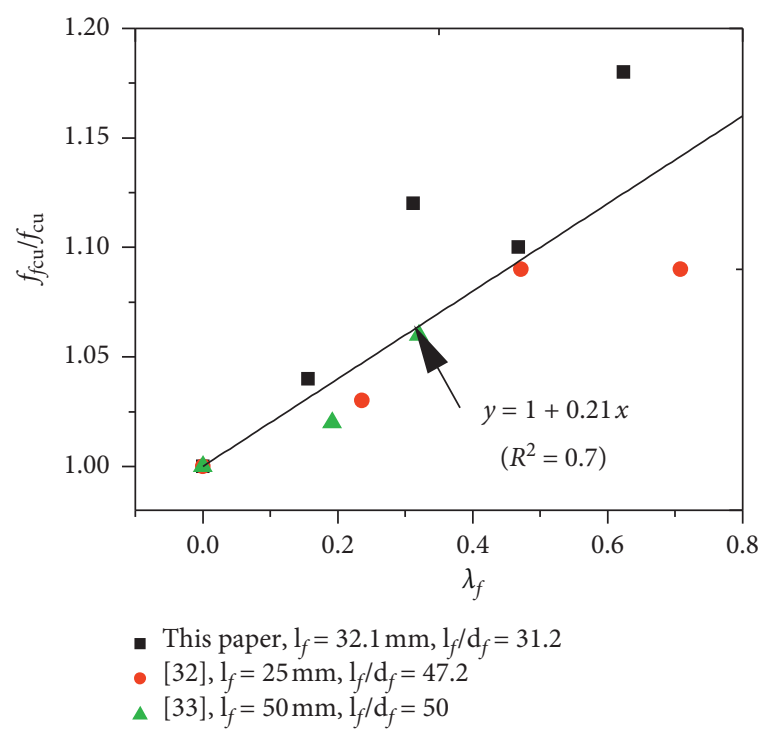

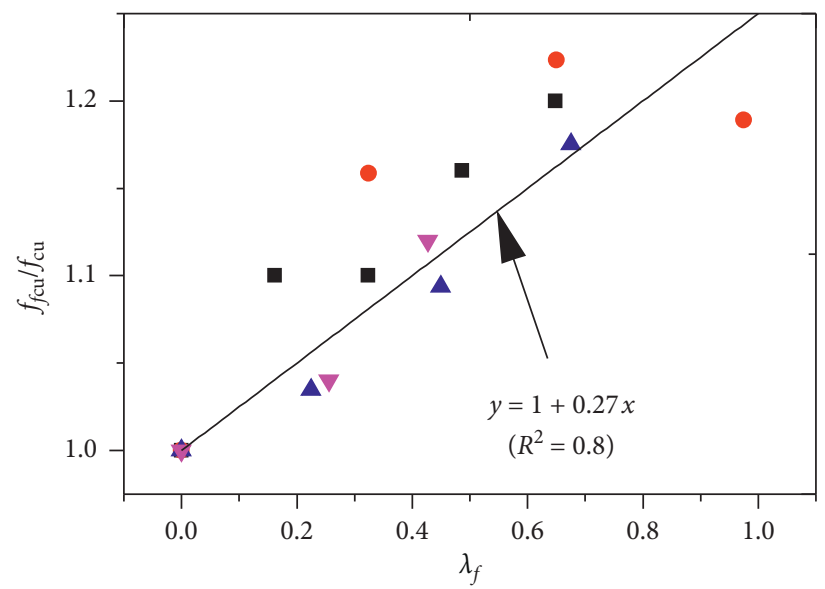

- This paper, $\mathrm{l}_{f}=32.3 \mathrm{~mm}, \mathrm{l}_{f} / \mathrm{d}_{f}=32.4$

- [13], $\mathrm{l}_{f}=40 \mathrm{~mm}, \mathrm{l}_{f} / \mathrm{d}_{f}=65$

$\Delta[16], \mathrm{l}_{f}=30 \mathrm{~mm}, \mathrm{l}_{f} / \mathrm{d}_{f}=45$

$\nabla[33], \mathrm{l}_{f}=60 \mathrm{~mm}, \mathrm{l}_{f} / \mathrm{d}_{f}=66.7$

(a)

(b)

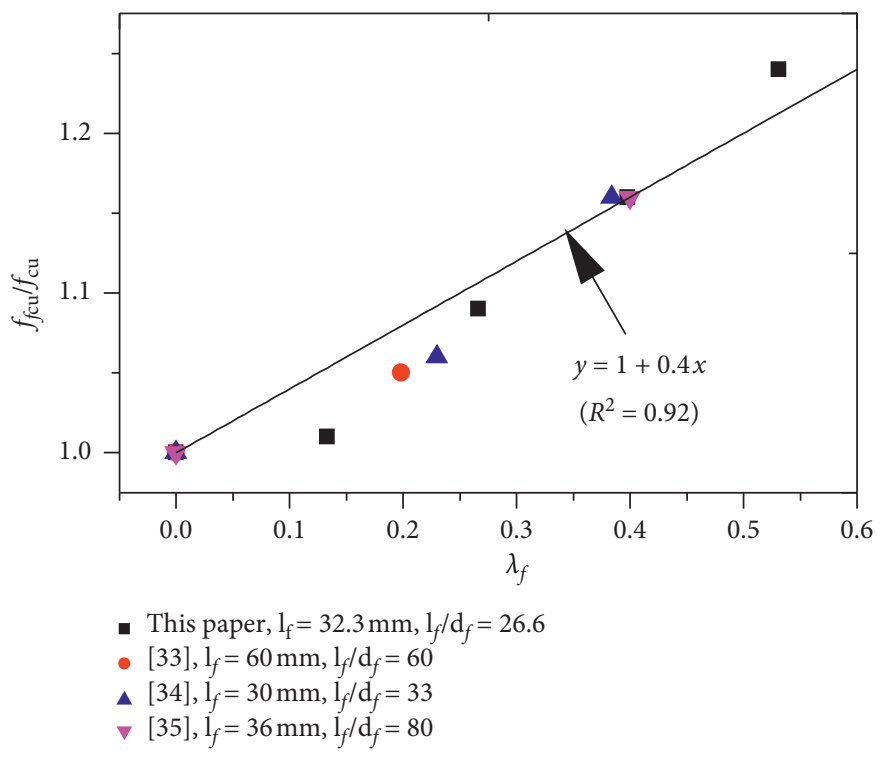

(c)

Figure 8: Relationship between $f_{\mathrm{fcu}} / f_{\mathrm{cu}}$ and $\lambda_{\mathrm{f}}$ (a) ST-F, (b) HE-F, and (c) CO-F.

the reinforcement ratio of $f_{\mathrm{fts}}, f_{\mathrm{fv}}$, and $f_{\mathrm{ftm}}$. The reinforcement ratio of $f_{\mathrm{fts}}, f_{\mathrm{fv}}$, and $f_{\mathrm{ftm}}$ can be expressed as follows:

$$
R_{\mathrm{f}}=1+\alpha_{\mathrm{f}} \alpha_{\mathrm{c}} \lambda_{\mathrm{f}}
$$

where $R_{\mathrm{f}}$ is strength reinforced ratio of SFRC; it can represent $f_{\mathrm{fts}} / f_{\mathrm{ts}}, f_{\mathrm{fv}} / f_{\mathrm{v}}$, or $f_{\mathrm{ftm}} / f_{\mathrm{tm}} ; \alpha_{\mathrm{c}}$ is the influence coefficient of concrete matrix, which is related to compressive strength of concrete matrix.

$\alpha_{c}$ can be obtained through the regression analysis of experiment data in this paper and previous literature $[13,16,21,32-36]$ based on equation (5). According to equation (4), $\alpha_{\mathrm{f}}$ is known: $\alpha_{\mathrm{f}}=0.21$ for ST-F; $\alpha_{\mathrm{f}}=0.27$ for HEF; $\alpha_{\mathrm{f}}=0.4$ for CO-F. The relationship between $R_{\mathrm{f}}$ and $\alpha_{\mathrm{f}} \lambda_{\mathrm{f}}$ is shown in Figure 9.
As shown in Figure 9, although the length and aspect ratio of steel fiber from different literature are different and $R_{\mathrm{f}}$ represents different strength reinforcement rates, such as $f_{\mathrm{fts}} / f_{\mathrm{ts}}, f_{\mathrm{fv}} / f_{\mathrm{v}}$, or $f_{\mathrm{ftm}} / f_{\mathrm{tm}}, R_{\mathrm{f}}$ showed a linear relationship with $\alpha_{\mathrm{f}} \lambda_{\mathrm{f}}$. This indicates that the reinforced effect of concrete matrix on the strength of SFRC is linear when eliminating the effect of steel fiber. As shown in Figure 9, the value of $\alpha_{c}$ can be obtained through linear regression with the experiment data, $\alpha_{c}=4.86$ and $R^{2}=0.87$. This shows that the correlation between $R_{\mathrm{f}}$ and $\alpha_{\mathrm{f}} \lambda_{\mathrm{f}}$ is fairly good. Since the compressive strength of plain concrete in this test is fixed $\left(f_{\mathrm{cu}}=34.6 \mathrm{MPa}\right)$, the value of $\alpha_{\mathrm{c}}$ could change with the changing of $f_{\mathrm{cu}}$. The relationship between $f_{\mathrm{cu}}$ and $\alpha_{\mathrm{c}}$ should be studied further for high strength concrete. 


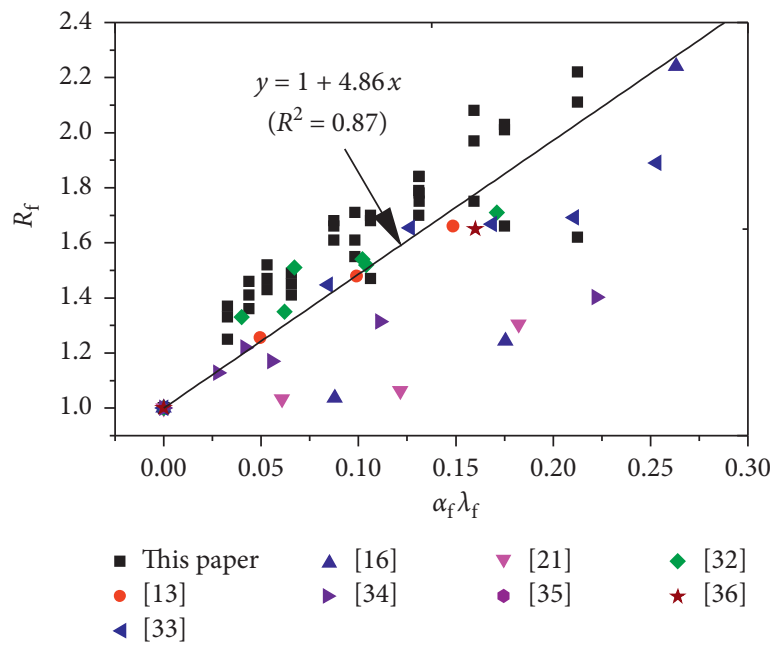

Figure 9: Relationship between $R_{\mathrm{f}}$ and $\alpha_{\mathrm{f}} \lambda_{\mathrm{f}}$.

TABLE 6: Calculated results and the comparison between calculated results and test results of mechanics strength.

\begin{tabular}{|c|c|c|c|c|c|c|c|c|}
\hline \multirow{2}{*}{ Mixture number } & \multicolumn{2}{|c|}{$f_{\text {fcu }}$} & \multicolumn{2}{|c|}{$f_{\mathrm{fts}}$} & \multicolumn{2}{|c|}{$f_{\mathrm{fv}}$} & \multicolumn{2}{|c|}{$f_{\mathrm{ftm}}$} \\
\hline & $\mathrm{Cal}(\mathrm{MPa})$ & $\mathrm{C} / \mathrm{T}$ & $\mathrm{Cal}(\mathrm{MPa})$ & $\mathrm{C} / \mathrm{T}$ & $\mathrm{Cal}(\mathrm{MPa})$ & $\mathrm{C} / \mathrm{T}$ & $\mathrm{Cal}(\mathrm{MPa})$ & $\mathrm{C} / \mathrm{T}$ \\
\hline $\mathrm{PC}$ & 34.6 & 1 & 3.15 & 1.00 & 6.85 & 1 & 4.32 & 1.00 \\
\hline ST-F0.5 & 35.7 & 0.99 & 3.65 & 0.87 & 7.94 & 0.85 & 5.01 & 0.93 \\
\hline ST-F1 & 36.9 & 0.95 & 4.15 & 0.93 & 9.03 & 0.89 & 5.70 & 0.91 \\
\hline ST-F1.5 & 38.0 & 1.00 & 4.66 & 0.95 & 10.12 & 0.92 & 6.38 & 0.86 \\
\hline ST-F2 & 39.1 & 0.96 & 5.16 & 0.97 & 11.21 & 0.92 & 7.07 & 0.89 \\
\hline HE-F0.5 & 36.1 & 0.95 & 3.82 & 0.89 & 8.32 & 0.83 & 5.24 & 0.86 \\
\hline HE-F1 & 37.6 & 0.99 & 4.49 & 0.86 & 9.76 & 0.89 & 6.16 & 0.85 \\
\hline HE-F1.5 & 39.1 & 0.97 & 5.16 & 0.89 & 11.22 & 0.92 & 7.08 & 0.94 \\
\hline HE-F2 & 40.7 & 0.98 & 5.83 & 0.91 & 12.68 & 1.11 & 7.99 & 0.92 \\
\hline CO-F0.5 & 36.4 & 1.04 & 3.96 & 0.85 & 8.62 & 0.88 & 5.44 & 0.83 \\
\hline CO-F1 & 38.3 & 1.02 & 4.78 & 0.90 & 10.39 & 1.03 & 6.55 & 0.89 \\
\hline CO-F1.5 & 40.1 & 1.00 & 5.59 & 0.85 & 12.16 & 1.01 & 7.67 & 0.90 \\
\hline $\mathrm{CO}-\mathrm{F} 2$ & 42.0 & 0.98 & 6.40 & 0.91 & 13.92 & 1.25 & 8.78 & 0.96 \\
\hline
\end{tabular}

Note that $\mathrm{Cal}$ stands for the calculated result and $\mathrm{C} / \mathrm{T}$ stands for the ratio of the calculated result with test result.

4.3. Formula Validation. Above is the main analysis of the enhancement effect of steel fiber. In order to verify the correctness of the equations (4) and (5) and regression coefficient of $\alpha_{\mathrm{f}}$ and $\alpha_{\mathrm{c}}$, the strength calculation method of $f_{\mathrm{fcu}}, f_{\mathrm{fts}}, \mathrm{f}_{\mathrm{fv}}$, and $\mathrm{f}_{\mathrm{ftm}}$ can be put forward based on equations (4) and (5):

$$
\begin{gathered}
f_{\mathrm{fcu}}=f_{\mathrm{cu}} \times\left(1+\alpha_{\mathrm{f}} \lambda_{\mathrm{f}}\right), \\
f_{\mathrm{fts}}=f_{\mathrm{ts}} \times\left(1+\alpha_{\mathrm{f}} \alpha_{\mathrm{c}} \lambda_{\mathrm{f}}\right), \\
f_{\mathrm{fv}}=f_{\mathrm{v}} \times\left(1+\alpha_{\mathrm{f}} \alpha_{\mathrm{c}} \lambda_{\mathrm{f}}\right), \\
f_{\mathrm{ftm}}=f_{\mathrm{tm}} \times\left(1+\alpha_{\mathrm{f}} \alpha_{\mathrm{c}} \lambda_{\mathrm{f}}\right),
\end{gathered}
$$

where $\alpha_{\mathrm{f}}=0.21$ for ST-F; $\alpha_{\mathrm{f}}=0.27$ for HE-F; $\alpha_{\mathrm{f}}=0.4$ for CO$\mathrm{F} ; \alpha_{\mathrm{c}}=4.86 ; \lambda_{\mathrm{f}}=V_{\mathrm{f}} l_{\mathrm{f}} / \mathrm{d}_{\mathrm{f}}$. Putting the test data of $f_{\mathrm{cu}}$ in $(6), \mathrm{f}_{\mathrm{ts}}$ in $(7), f_{\mathrm{v}}$ in $(8)$, and $f_{\mathrm{tm}}$ in (9), the calculated value of $f_{\mathrm{fcu}}, f_{\mathrm{fts}}, f_{\mathrm{fv}}$, and $f_{\mathrm{ftm}}$ and the ratio of calculated value to test value are put into Table 6.

The ratio of calculated value to test value of $f_{\text {fcu }}$ varies from 0.95 to 1.04 ; this indicates that calculated value of $f_{\mathrm{fcu}}$ coincides with test value quite well. The ratio of calculated value to test value of $f_{\mathrm{fts}}$ and $f_{\mathrm{ftm}}$ varies from 0.85 to 1 . Although the calculated value is slightly less than test value, the calculated value is still close to the test value. Except CO$\mathrm{F} 2$, the ratio of calculated value to test value of $f_{\mathrm{fv}}$ varies from 0.83 to 1.11 ; the calculated value is also close to the test value. According to the previous analysis, when $V_{\mathrm{f}}$ is larger than $1.5 \%$, the enhancement effect of steel fiber becomes weak, but in the calculation of equation (8) this can not reflect this character, so when $V_{\mathrm{f}}$ is $2 \%$, the calculated value is larger than the test value. Further research should be taken for SFRC with steel fiber volume fraction that is above $2 \%$.

\section{Conclusions}

The general objective of this research project was to evaluate the effect of steel fiber shape and content on the mechanical property of SFRC and the calculation method of reinforced effect of steel fiber with different shape and content on compressive strength, splitting strength, shear strength, and flexural strength. The main conclusions are as follows: 
(1) Expecting that shear strength gets its maximum value at steel fiber volume ratio which is $1.5 \%$, compressive strength, splitting strength, and flexural strength all express linear increase trend with the increasing of steel fiber volume ratio from 0 to $2 \%$.

(2) When the steel fiber content is fixed, CO-F has the best reinforced effect on compressive strength, splitting strength, shear strength, and flexural strength of SFRC; HE-F takes the second place and ST-F is the least.

(3) In order to increase the reinforcement of steel fiber on concrete, the steel fiber has rough surface which is the best choice. At least, interface bonding force should be increased as far as possible.

(4) Two influence factors $\alpha_{\mathrm{f}}$ and $\alpha_{\mathrm{c}}$ were put forward and their value was obtained by regression analysis of experiment data. The proposed calculated formulas for compressive strength, splitting tensile strength, shear strength, and flexural strength of SFRC have good agreement with the experimental results.

(5) When steel fiber volume fraction is larger than $2 \%$, the reinforced effect of steel fiber on shear strength needs to be studied further. Relationship between $f_{\text {cu }}$ and $\alpha_{c}$ should also be researched further for high strength concrete $\left(f_{\mathrm{cu}} \geq 60 \mathrm{MPa}\right)$.

\section{Data Availability}

The experimental data used to support the findings of this study are included within the article.

\section{Conflicts of Interest}

The authors declare that there are no conflicts of interest regarding the publication of this paper.

\section{Acknowledgments}

This research was supported by China National Natural Science Foundation Youth Fund Project (51808509), Innovation Team Development Plan of China's Ministry of Education (IRT_16R67), Key Scientific Research Projects of Colleges and Universities of Henan Provincial Department of Education (19A560005) and Thousand Talents Plan in Henan Province (ZYQR201912029).

\section{References}

[1] P. Zhang, S. Fu, K. Zhang, and T. Zhang, "Mechanical properties of polyvinyl alcohol fiber-reinforced concrete composite containing fly ash and nano- $\mathrm{SiO}_{2}$," Science of Advanced Materials, vol. 10, no. 6, pp. 769-778, 2018.

[2] D. Niu, L. Jiang, M. Bai, and Y. Miao, "Study of the performance of steel fiber reinforced concrete to water and salt freezing condition," Materials \& Design, vol. 44, pp. 267-273, 2013.

[3] P. Zhang, Q.-F. Li, J. Wang, Y. Shi, and Y.-F. Ling, "Effect of PVA fiber on durability of cementitious composite containing nano-SiO ${ }_{2}$," Nanotechnology Reviews, vol. 8, no. 1 , pp. 116-127, 2019.
[4] F. Bencardino, L. Rizzuti, G. Spadea, and R. N. Swamy, "Stress-strain behavior of steel fiber-reinforced concrete in compression," Journal of Materials in Civil Engineering, vol. 20, no. 3, pp. 255-263, 2008.

[5] L. Carabba, M. Santandrea, C. Carloni, S. Manzi, and M. C. Bignozzi, "Steel fiber reinforced geopolymer matrix (S-FRGM) composites applied to reinforced concrete structures for strengthening applications: a preliminary study," Composites Part B: Engineering, vol. 128, pp. 83-90, 2017.

[6] M. T. Kazemi, H. Golsorkhtabar, M. H. A. Beygi, and M. Gholamitabar, "Fracture properties of steel fiber reinforced high strength concrete using work of fracture and size effect methods," Construction and Building Materials, vol. 142, pp. 482-489, 2017.

[7] S. Tayfur, N. Alver, S. Abdi, S. Saatc1, and A. Ghiami, "Characterization of concrete matrix/steel fiber de-bonding in an SFRC beam: principal component analysis and $k$-mean algorithm for clustering $\mathrm{AE}$ data," Engineering Fracture Mechanics, vol. 194, pp. 73-85, 2018.

[8] P. Zhang, Q. F. Li, Y. Z. Chen, Y. Shi, and Y. F. Ling, "Durability of steel fiber-reinforced concrete containing $\mathrm{SiO}_{2}$ nano-particles," Materials, vol. 12, no. 13, pp. 1-18, 2019.

[9] H. Wu, G. M. Ren, Q. Fang, and J. Z. Liu, "Effects of steel fiber content and type on dynamic tensile mechanical properties of UHPCC," Construction and Building Materials, vol. 173, pp. 251-261, 2018.

[10] A. Khabaz, "Analysis of sliding mechanism of straight steel fibers in concrete and determine the effect of friction," Archives of Civil and Mechanical Engineering, vol. 17, no. 3, pp. 599-608, 2017.

[11] A. Khabaz, "Monitoring of impact of hooked ends on mechanical behavior of steel fiber in concrete," Construction and Building Materials, vol. 113, pp. 857-863, 2016.

[12] G. M. Ren, H. Wu, Q. Fang, and J. Z. Liu, "Effects of steel fiber content and type on static mechanical properties of UHPCC," Construction and Building Materials, vol. 163, pp. 826-839, 2018.

[13] W. Abbass, M. I. Khan, and S. Mourad, "Evaluation of mechanical properties of steel fiber reinforced concrete with different strengths of concrete," Construction and Building Materials, vol. 168, pp. 556-569, 2018.

[14] S.-J. Jang and H.-D. Yun, "Combined effects of steel fiber and coarse aggregate size on the compressive and flexural toughness of high-strength concrete," Composite Structures, vol. 185, pp. 203-211, 2018.

[15] E. Güneyisi, M. Gesoğlu, A. O. M. Akoi, and K. Mermerdaş, "Combined effect of steel fiber and metakaolin incorporation on mechanical properties of concrete," Composites Part B: Engineering, vol. 56, pp. 83-91, 2014.

[16] Ş. Yazıc1, G. İnan, and V. Tabak, "Effect of aspect ratio and volume fraction of steel fiber on the mechanical properties of SFRC," Construction and Building Materials, vol. 21, no. 6, pp. 1250-1253, 2007.

[17] B. Boulekbache, M. Hamrat, M. Chemrouk, and S. Amziane, "Influence of yield stress and compressive strength on direct shear behaviour of steel fibre-reinforced concrete," Construction and Building Materials, vol. 27, no. 1, pp. 6-14, 2012.

[18] T. Soetens and S. Matthys, "Shear-stress transfer across a crack in steel fibre-reinforced concrete," Cement and Concrete Composites, vol. 82, pp. 1-13, 2017.

[19] A. Khabaz, "Performance evaluation of corrugated steel fiber in cementitious matrix," Construction and Building Materials, vol. 128, pp. 373-383, 2016. 
[20] D.-Y. Yoo and Y.-S. Yoon, "Structural performance of ultrahigh-performance concrete beams with different steel fibers," Engineering Structures, vol. 102, pp. 409-423, 2015.

[21] S.-C. Lee, J.-H. Oh, and J.-Y. Cho, "Compressive behavior of fiber-reinforced concrete with end-hooked steel fibers," Materials, vol. 8, no. 4, pp. 1442-1458, 2015.

[22] D.-Y. Yoo, S.-T. Kang, and Y.-S. Yoon, "Effect of fiber length and placement method on flexural behavior, tension-softening curve, and fiber distribution characteristics of UHPFRC," Construction and Building Materials, vol. 64, pp. 67-81, 2014.

[23] K. Wille, D. J. Kim, and A. E. Naaman, "Strain-hardening UHP-FRC with low fiber contents," Materials and Structures, vol. 44, no. 3, pp. 583-598, 2011.

[24] Z. Wu, K. H. Khayat, and C. Shi, "How do fiber shape and matrix composition affect fiber pullout behavior and flexural properties of UHPC?" Cement and Concrete Composites, vol. 90, pp. 193-201, 2018.

[25] P. Zhang, Y. Ling, J. Wang, and Y. Shi, "Bending resistance of PVA fiber reinforced cementitious composites containing nano-SiO ${ }_{2}, "$ Nanotechnology Reviews, vol. 8, no. 1, pp. 690-698, 2019.

[26] S. A. C. Aqsiq, Common Portland Cement, GB/175-2007, Beijing, China, 2007.

[27] S. A. C. Aqsiq, Pebble and Crushed Stone for Construction, GB/ T 14685, Beijing, China, 2011.

[28] Mohurd, Specification for Mix Proportion Design of Ordinary Concrete, JGJ 55-2011, China Architecture \& Building Press, Beijing, China, 2011.

[29] Mohurd, Steel Fiber Reinfroced Concrete, JG/T 472-2015, Beijing, China, 2015.

[30] Aqsiq, Standard for Test Method of Mechanical Properties on Ordinary Concrete, GB/T50081, Beijing, China, 2002.

[31] ASTM, Standard Test Method for Flexural Performance of Fiber-Reinforced Concrete (Using Beam With Third-Point Loading), C1609, Beijing, China, 2012.

[32] G. Appa Rao and A. Sreenivasa Rao, "Toughness indices of steel fiber reinforced concrete under mode II loading," $M a$ terials and Structures, vol. 42, no. 9, pp. 1173-1184, 2009.

[33] M. N. Soutsos, T. T. Le, and A. P. Lampropoulos, "Flexural performance of fibre reinforced concrete made with steel and synthetic fibres," Construction and Building Materials, vol. 36, pp. 704-710, 2012.

[34] Y. Zhang, Z. Li, X. Liu et al., "Experiment on tension-compression ratio of steel fiber reinforced concrete," Journal of Jiangsu University (Natural Science Edition), vol. 38, no. 6, pp. 719-723, 2017.

[35] R. Perumal, "Correlation of compressive strength and other engineering properties of high-performance steel fiber-reinforced concrete," Journal of Materials in Civil Engineering, vol. 271 pages, 2015.

[36] F. Hasan-Nattaj and M. Nematzadeh, "The effect of forta-ferro and steel fibers on mechanical properties of high-strength concrete with and without silica fume and nano-silica," Construction and Building Materials, vol. 137, pp. 557-572, 2017. 